\title{
Hein Kötz
}

\section{Europäisches Vertragsrecht}

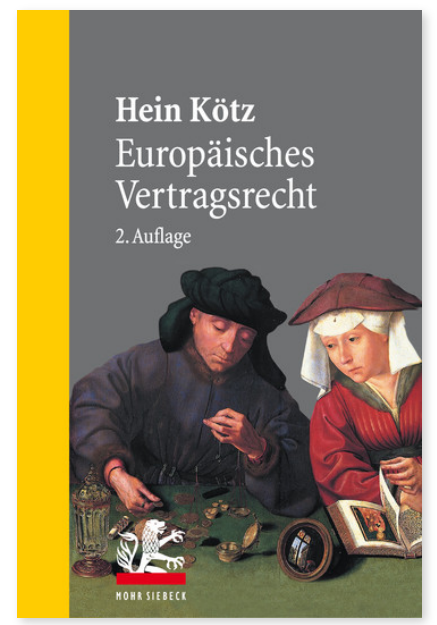

2., aktualisierte und vervollständigte Auflage; 2015. XIV, 535 Seiten. MLB

\section{ISBN 978-3-16-153768-4}

DOI 10.1628/978-3-16-153768-4

eBook PDF 39,00€

ISBN 978-3-16-153767-7

fadengeheftete Broschur 39,00€
Unter »Europäischem Vertragsrecht« versteht dieses Buch die Regeln, die den Rechtsordnungen der europäischen Länder gemeinsam sind: Wie kommt ein gültiger Vertrag zustande? Nach welchen Regeln wird beurteilt, ob eine Vertragspartei die Erfüllung des Vertrages verlangen, von dem Vertrag Abstand nehmen, ihn widerrufen oder kündigen oder den Kontrahenten auf Schadensersatz in Anspruch nehmen kann? Lassen sich auf dem Gebiet des Vertragsrechts gemeineuropäische Strukturen auffinden? Gibt es allgemein akzeptierte Regeln? Wie sind sie zu formulieren, wenn man die »Prinzipien des Europäischen Vertragsrechts« oder die Vorschläge des »Draft Common Frame of Reference« berücksichtigt? Dabei werden die Lösungen der nationalen Rechtsordnungen ausführlich - wenn auch stets nur als nationale Variationen eines europäischen Themas - behandelt. Das Buch kann deshalb bei der rechtsvergleichenden Ausbildung der jungen europäischen Juristen eine Rolle spielen, ferner auch dort, wo es um die Vorbereitung europäischen Gesetzesrechts oder um die Reform der nationalen Vertragsrechte geht. Das Buch ist in einer ersten unvollständigen Auflage schon 1996 erschienen. Die Neuauflage bringt den Text auf den neuen Stand und ergänzt ihn um die damals noch fehlenden Abschnitte.

Das Werk wurde als eines der 'Juristischen Bücher des Jahres' 2015 ausgewählt. »Ein echtes Pionierwerk, das die Grundlage eines grenzübergreifenden europäischen wissenschaftlichen Diskureses und Rechtsunterrichts bieten könnte [...] « (NJW41/2015, 3014)

Für Bibliotheken gelten bei diesem Titel abweichende Konditionen; bitte wenden Sie sich an den Vertrieb.

Hein Kötz Geboren 1935; 1971-78 Professor an der Universität Konstanz; 1978-2000 Professor an der Universität Hamburg und Direktor am Max-Planck-Institut für ausländisches und internationales Privatrecht; 2000-04 Gründungspräsident der Bucerius Law School.

Jetzt bestellen:

https://mohrsiebeck.com/buch/europaeisches-vertragsrecht-9783161537684?no_cache=1

order@mohrsiebeck.com

Telefon: +49 (0)7071-923-17

Telefax: +49 (0)7071-51104 